\title{
Determination of the Validity and Reliability of a Modified Osteoporosis Health Belief Scale and Osteoporosis Self-Efficacy Scale to Include Vitamin D
}

\author{
Alexa L. Evenson ${ }^{1}$ and Gregory F. Sanders ${ }^{2}$ \\ ${ }^{1}$ The College of Saint Benedict/Saint John's University \\ ${ }^{2}$ North Dakota State University
}

\begin{abstract}
Background/Purpose: Osteoporosis health beliefs and osteoporosis self-efficacy scales are commonly used in determining educational needs towards osteoporosis prevention but lack vitamin D content. This study examined the validity and reliability of Osteoporosis Health Belief Scale (OHBS) and Osteoporosis Self Efficacy Scale (OSES) modified scales which included vitamin D content in order to be used in studies to increase vitamin $\mathrm{D}$ and calcium intakes for prevention of osteoporosis.

Methods: Participants were a convenience sample of 153 college-aged adults at a Midwestern university. Factor analysis, Cronbach $\alpha$, and Intra-class correlation coefficients determined validity, internal consistency, and test-retest reliability of the modified scales.

Results: The OHBS-D Cronbach $\alpha$ was $r=.82$; subscales ranged from .75-.87. The OSES-D Cronbach $\alpha$ was $r=.98$; subscales ranged from .96-.98. Total ICC for OHBS-D and OSES-D was .79 and .97 respectively. Factor analysis extracted eight factors for the OHBS-D and three factors for the OSES-D, which explained $52.2 \%$ and $82.2 \%$ of the total variance in all variables accounted for by each factor respectively.

Conclusion: The modified scales were valid and reliable indicating they could be used to determine osteoporosis related health beliefs and self-efficacy.

(C) 2015 Californian Journal of Health Promotion. All rights reserved.

Keywords: health beliefs, self-efficacy, vitamin D, reliability, osteoporosis
\end{abstract}

\section{Introduction}

Osteoporosis, a public health risk for approximately 34 million Americans (National Osteoporosis Foundation [NOF], 2008), is a disease where bones lose mass and can deteriorate over time, causing them to weaken and become more susceptible to fractures (NOF, 2008). The significance of osteoporosis prevention has been widely studied. The importance of obtaining peak bone mass and bone strength early in life may provide the greatest protection against osteoporosis in later life (Lloyd, Petit, Lin, \& Beck, 2004). Risk factors that may increase the possibility of an individual developing osteoporosis include nonmodifiable and modifiable risk factors. Nonmodifiable risk factors include advanced age, female gender, non-Hispanic White race, and family history of osteoporosis or fracture
(Robitaille et al., 2008). Modifiable risk factors include insufficient dietary intake of calcium and vitamin $\mathrm{D}$, an inactive lifestyle, low body weight, alcohol use, and smoking (Robitaille et al., 2008; Dell, Green, Anderson, \& Williams, 2009). Osteoporosis preventive actions can be implemented throughout the lifespan in order to decrease the risk of developing low bone density. These preventative actions should begin as early in life as possible to reduce the risk of developing osteoporosis since peak bone mass (PBM) is attained around age 30 (Heaney et al., 2000).

\section{Expanded Health Belief Model}

The four-stage expanded health belief model (EHBM) reflects the foundation that preventive behaviors (i.e. adequate dietary vitamin D intake) result from the direct and indirect influences of knowledge, attitudes, and self- 
efficacy (Rosenstock, Strecher, \& Becker, 1988). Bandura (1977) has defined self-efficacy as an individual's belief of his or her capability to implement an action in order to achieve a specified goal. The EHBM suggests that an individual is more likely to carry out an action (e.g., consume adequate vitamin D) if he or she believes they are vulnerable to osteoporosis and if they develop osteoporosis, they could lose independence. Next, the individual might perceive the benefits of taking action as outweighing the barriers or costs. Finally, overall health motivation and self-efficacy may contribute to an individual taking action. The EHBM was used to develop the original Osteoporosis Health Belief Scale (OHBS) and Osteoporosis Self-Efficacy Scale (OSES).

Health beliefs are often related to osteoporosis preventive behaviors such as obtaining adequate dietary calcium (Chang, 2006; Cline \& Worley, 2006). Additionally, osteoporosis self-efficacy may play a role in behavior change such as increasing dietary calcium and vitamin D intake or changing behavior (Tussing \& ChapmanNovakofski, 2005; Wallace, 2002). Osteoporosis health beliefs that also include self-efficacy and their association with vitamin $\mathrm{D}$ have not been studied in detail. Beliefs about osteoporosis are often measured using Kim, Horan, Gendler, and Patel's (1991) Osteoporosis Health Belief Scale (OHBS).

\section{Measuring Osteoporosis Health Beliefs and Self-Efficacy}

Osteoporosis self-efficacy is commonly assessed using Horan, Kim, Gendler, Froman, and Patel's (1998) Osteoporosis Self-Efficacy Scale (OSES). Similarly to the OHBS, the OSES does not include osteoporosis selfefficacy related vitamin D items and could be revised in order to determine self-efficacy of vitamin D intake, as this is an integral role in preventing osteoporosis.

The original OHBS and OSES have been used with samples of college aged females (Ziccardi, Sedlak, Doheny, 2004); older adult males age 65 and older (Sedlak, Doheny, \& Estok, 2000), postmenopausal white females (Sedlak, Doheny, Estok, Zeller, \& Winchell, 2007) and a sample of college age males and females (Gammage, Francoeur, Mack, \& Klentrou, 2009). Additionally, the original OHBS and OSES have been used to assess health beliefs including self-efficacy among different age cohorts and both genders (Johnson, McLeod, Kennedy, \& McLeod, 2008).

\section{The Current Study}

Because of the lack of measures including vitamin $\mathrm{D}$ beliefs and self-efficacy, the aim of the current study was to determine construct validity and reliability (internal consistency and test-retest reliability) of an Osteoporosis Health Belief Scale and an Osteoporosis Self-Efficacy Scale modified to include vitamin $\mathrm{D}$ related items. The OHBS-D scale was designed to measure health beliefs related to osteoporosis including vitamin D items. Additionally, the OSES-D scale was designed to measure selfefficacy related to osteoporosis with additional vitamin D items. Again, no other scales have been developed to measure vitamin $\mathrm{D}$ related health beliefs and self-efficacy associated with osteoporosis in an adult population.

\section{Methods}

\section{Study Design}

This cross-sectional study was part of a larger study on the influence of educational interventions on osteoporosis preventative behaviors. The study was reviewed and approved by both the College of Saint Benedict/Saint John's University and North Dakota State University's institutional review boards.

Participants were recruited through six sections (approximately 30 students each) of the same introductory nutrition course. While these sections were randomly assigned into three groups (control, treatment group 1, or treatment group 2) for a separate analysis of related to educational interventions, they were analyzed as a total group $(n=153)$ to assess validity of the osteoporosis scales. Only data from the control group $(n=51)$ was used to determine internal consistency and test-retest reliability of the scales to avoid the impact of the educational intervention. This introductory nutrition course 
was chosen for the current study as the course included and discussed osteoporosis information and prevention.

\section{Participants}

Participants ( $\mathrm{n}=153$; young adults ages 18-23) were recruited through in class and email announcements. Exclusion criteria included those under the age of 18 . The response rate was $84.4 \%$. The sample in this study included 41 males (27\%) and 112 females (73\%). Compared to the university population, this sample was skewed towards females as the university is comprised of $47 \%$ males and $53 \%$ females. However, the sample was a representative sample of the students enrolled in the introductory nutrition course (30\% male; $70 \%$ female).

\section{Measures}

The original OHBS and OSES were chosen because they have been shown to be valid and reliable. They have been used in multiple studies that included participants ranging from college-aged students to older adults, and previous studies included both males and females although samples sizes have been relatively small, ranging from 46-201 participants (Chan et al., 2007; Horan et al., 1998; Kim et al., 1991; Mack, Gammage \& Klent, 2006; Tussing \& Chapman-Novakofski, 2005). Permission to use and modify the original Osteoporosis Health Belief Scale (OHBS) and the original Osteoporosis SelfEfficacy Scale (OSES) was granted by Dr. Phyllis Gendler at Grand Valley State University.

Original Osteoporosis Health Belief Scale. The original OHSB is a 42-item instrument which uses a 5-point Likert scale from 'strongly agree' to 'strongly disagree.' The original OHBS includes seven subscales: Susceptibility (items 1-6), Seriousness (items 7-12), BenefitsExercise (items 13-18), Benefits-Calcium (items 19-24), Barriers-Exercise (items 25-30), Barriers-Calcium (items 31-36) and Health Motivation (items 37-42). An example question for each subscale is as follows: "You feel your chances of getting osteoporosis in the future are good” (Susceptibility); "If you had osteoporosis, your whole life would change” (Seriousness); "Eating calcium rich foods requires changing your dietary habits which is difficult" (BarriersCalcium); "Eating Calcium rich foods reduces the risks of broken bones" (Benefits-Calcium); "Exercising regularly would mean starting a new habit which is hard for you to do" (Barriers to Exercise); "You feel better when you exercise to prevent osteoporosis" (Benefits to Exercise); and "You frequently do things to improve your health” (Health Motivation).

The original OHBS has been found to be valid and reliable (Kim et al., 1991; Horan et al., 1998). Construct validity of the original OHBS was established using factor analysis (Kim et al., 1991) which extracted five factors that accounted for $49.3 \%$ of the total variance. The original five factors included susceptibility, barriers, benefits, seriousness, and health motivation. However, while the authors identified these original five factors, they also discussed that the factors of benefits and barriers could be split for calcium and exercise resulting in two additional subscales. Therefore, most researchers use seven subscales which include susceptibility, seriousness, health motivation, benefits of calcium, benefits of exercise, barriers of calcium, and barriers of exercise (Chan, Kwong, Zang, \& Wan, 2007; Tussing \& Chapman-Novakofski, 2005; Cline \& Worley, 2006).

The original OHBS Cronbach alphas for the subscales in the original development study ranged from .61-.80, which established an acceptable level of internal consistency reliability (Kim et al., 1991) Subscale reliabilities from additional studies have ranged from .76-.92 (Sedlak et al., 2007; Sedlak et al., 2000). The original OHBS test-retest reliability for the total instrument was .90 (Kim et al., 1991) indicating that reliability was quite high. Additional studies have found slightly lower but still strong test-retest reliability for the total instrument to be .77-.84 (Sedlak et al., 2007; Sedlak et al., 2000).

Modification of Osteoporosis Health Belief Scale - OHBS-D. In the current study, the original OHBS was modified to include two 
additional subscales. These subscales included: Benefits-Vitamin D (items 43-48) and BarriersVitamin D (items 49-54). The vitamin D questions were modeled after the original scale's calcium questions. The modified scale with vitamin D related content was named OHBS-D. The OHBS-D used a 5-point Likert scale from 'strongly agree' to 'strongly disagree' which was comparable to the original scale. Possible scores for each subscale ranged from 6 to 30 with a low score indicating a low perception and a high score indicating a high perception. Possible total scores ranged from 54-270.

Original Osteoporosis Self-Efficacy Scale. The original OSES used a 21-item survey consisting of two subscales, an osteoporosis selfefficacy exercise scale and a calcium scale. Kim et al. (1991) originally developed the selfefficacy scale as a line scale from "not at all confident" to "very confident". The subjects were to mark on the line closer to "not at all confident” if they did not feel confident up to "very confident" as their confidence rose. Examples of questions for both the exercise and calcium subscales include: How confident are you that you will "Begin a new or different exercise program.”(Exercise) and "Eat calciumrich foods on a regular basis" (Calcium). The possible scores of the scale ranged from 0 for "not at all confident" to 100 for "very confident."

The original OSES was developed by Horan et al. (1998). Construct validity was established by factor analysis that extracted two factors: calcium and exercise. Criterion related validity was established by examining calcium intake and exercise. The original authors deemed the original OSES valid based on criterion related validity and factor analysis (Horan et al., 1998). Additionally, the original authors evaluated testretest reliability and found this to be .90 for the overall scale indicating reliability was quite strong (Horan et al., 1998). Additional studies have agreed with these results, finding the total test-retest reliability for the OSES to be .95 and .96 (Sedlak et al., 2007; Sedlak et al., 2000). Subscale test-retest reliability was found to be .76-.92 (Sedlak et al., 2007) and .96-.96 (Sedlak et al., 2000) indicating that the OSES is testretest reliable. Additionally, internal consistency estimates were $r=.94$ for the exercise subscale and $r=.93$ for the calcium subscale.

Modified Osteoporosis Self-Efficacy Scale OSES-D. In the current study, the original OSES was modified to include an additional subscale of vitamin D related content that included 11 items. The vitamin D questions were modeled after the original scale's calcium items. The modified scale was named OSES-D. The OSES-D was adapted to an online format where participants were asked to mark a spot on the line, thus keeping the line scale. A computergenerated scale was used to score the mark on a $10 \mathrm{~cm}$ line. This OSES-D included a total of 32 items and a total maximum score for the OSESD was 3200.

\section{Procedures and Analysis}

The OHBS-D and OSES-D baseline and posttest were administered on-line approximately nine weeks apart. Participants were emailed the survey link and were allowed five days to complete the survey. Participants were offered 15 points $(1.8 \%$ of total points in the course and prorated for completing the baseline and posttest surveys) for extra credit for completing both the baseline and post-test surveys. Statistical analyses were conducted using SPSS (version 19.0, SPSS, Inc., Chicago, IL, 2010). Participant demographics were summarized using frequencies and percentages. Chi-square was used to determine whether the participants were equally distributed in regard to demographic characteristics.

Validity. To determine the validity of the OHBS-D, two steps were taken. Step one consisted of determining content validity of vitamin D related items for the OHBS-D scale. This was established by identifying the domain of content through a comprehensive review of the literature and input from nursing, nutrition, and human development faculty members. Step two was to conduct a factor analysis of the OHBS-D in order to validate the original structure with the modified vitamin D items. Exploratory factory analysis was conducted using principle component analysis with 
varimax rotation. The scree plot and magnitude of the eigenvalues were used to determine the number of factors that could be extracted. In accordance with the original scale development, factor loadings of $<0.35$ were omitted (Horan et al., 1998). To determine the validity of the OSES-D, the same two steps for determining the validity of the OHBS-D were used.

Reliability. To determine the reliability of the OHBS-D two analyses were conducted using the control group $(n=51)$. Step one consisted of calculating Cronbach $\alpha$ as an indicator of internal consistency reliability for the OHBS-D scale. A Cronbach $\alpha$ coefficient of $r \geq .70$ was considered adequate internal consistency reliability (Nunnally \& Bernstein, 1994). Step two consisted of using item-total statistics that were calculated using data from baseline to evaluate the contribution of each item to the total score. An $r \geq .30$ was considered an adequate item-total correlation (Nunnally \& Bernstein, 1994). Step three consisted of determining the intra-class correlation coefficients (ICC) to assess test-retest reliability of the OHBS-D. An ICC of $>.70$ was considered adequate test-retest reliability (Weir, 2005). Additionally, an ICC of .60-.79 was considered stable with and ICC $>.80$ being considered exceptional (March \& Sullivan, 1999). The OSES-D followed the same three steps to determine internal consistency and testretest reliability as was undertaken with the OHBS-D using the control group participants.

\section{Results}

\section{Demographics}

One hundred fifty-three undergraduate students ages 18-23 participated in the study including 41 males (27\%) and 112 females (73\%). The majority of the participants were Caucasian (81\%) followed by Asian or Pacific Islander (9\%), Hispanic/Latino (5\%), African American (4\%) and American Indian or Alaska Native (1\%) Almost all participants were single (98\%). Participants mainly lived on campus (59\%) and purchased the majority of their food at the campus cafeterias. The remaining participants (41\%) lived in campus apartments and purchased the majority of their food from local grocery stores.

A majority of the participants exercised (88\%) and $31 \%$ took some type of dietary supplement. The majority of the sample did not know anyone with osteoporosis (79\%), and did not have a relative with osteoporosis (86\%). Of those who did have a relative with osteoporosis (14\%), $47 \%$ said that it was a blood relative.

\section{Validity}

Modified Osteoporosis Health Belief ScaleOHBS-D. At baseline, no significant differences were found in the OHBS-D or the OSES-D between participants in the control group and experimental groups. Content validity was established by modeling the addition of vitamin $\mathrm{D}$ content after the original calcium content in the scale. In addition, four faculty members were all in agreement of the content of the additional questions added to the scale. Factor analysis was used to evaluate the validity of the original OHBS structure as well as the additional vitamin D items. For factor analysis, the first 13 eigenvalues exceeded 1.0; however, the scree plot showed eight sharp bends and thus eight factors were identified. Eigenvalues of greater than 1.0 may possibly overestimate factors; therefore the scree plot was used for a more accurate factor extraction (Costello \& Osborne, 2005). Eight factors explained $58.2 \%$ of the total variance, thus with additional vitamin $\mathrm{D}$ content accounted for more of the total variance compared to the original scale. Factors extracted included susceptibility, seriousness, health motivation, benefits to exercise, benefits to calcium and vitamin D, barriers to exercise, barriers to calcium, and barriers to vitamin $\mathrm{D}$. These factors extracted were identical to the original scale with the exceptions of two factors: 1) benefits of calcium and vitamin D and 2) barriers to vitamin D. All items related to a specific concept loaded under the specific subscale except benefits to calcium and benefits to vitamin $\mathrm{D}$ were combined. Each item loaded meaningfully on only one factor; and each factor had multiple, significant item loadings. Factor loadings for each item in the subscales are found in Table 1 and ranged from .38-.85. 
Table 1.

Factor Loadings for the OHBS-D Including Vitamin D Related Items

\section{Item Loading}

Factor 1 Susceptibility

1. Your chances of getting osteoporosis are high.

2. Because of your body build, you are more .64

3. It is extremely likely that you will get

4. There is a good chance that you will get .85

5. You are more likely than the average person to $\quad .81$

6 . Your family history makes it more likely that .65 Factor 2 Seriousness

7. The thought of having osteoporosis scares

8. If you had osteoporosis you would be

9. Your feelings about yourself would change

10. It would be very costly if you got .76

11. When you think about osteoporosis you get .67

12. It would be very serious if you got .76 Factor 3 Benefits of Exercise

13. Regular exercise prevents problems that .66

14. You feel better when you exercise to .75

15. Regular exercise helps you build strong .85

16. Exercising to prevent osteoporosis also .77

17. Regular exercise cuts down on the chances .57

18. You feel good about yourself when you Factor 4 Benefits of Calcium and Vitamin D

19. Taking ENOUGH CALCIUM prevents .42

20. You have lots to gain from taking in .40

21. Taking in ENOUGH CALCIUM prevents .69

22. You would not worry as much about .57

23. Taking in ENOUGH CALCIUM cuts

24. You feel good about yourself when you .38

25. Taking ENOUGH VITAMIN D prevents .66

26. You have lots to gain from taking in .61 .59

27. Taking in ENOUGH VITAMIN D

\begin{tabular}{|c|c|}
\hline \multicolumn{2}{|l|}{ Item Loading (cont’d) } \\
\hline 28. You would not worry as much about & .79 \\
\hline 29. Taking in ENOUGH VITAMIN D cuts & .81 \\
\hline 30. You feel good about yourself when you & .74 \\
\hline \multicolumn{2}{|l|}{ Factor 5 Barriers to Exercise } \\
\hline 31. You feel like you are not strong enough to & .62 \\
\hline 32. You have no place where you can exercise. & .67 \\
\hline 33. Your significant other or family & .57 \\
\hline 34. Exercising regularly would mean starting a & .71 \\
\hline 35. Exercising regularly makes you & .83 \\
\hline 36. Exercising regularly upsets your everyday & .72 \\
\hline \multicolumn{2}{|l|}{ Factor 6 Barriers to Calcium } \\
\hline 37. Calcium rich foods cost too much. & .70 \\
\hline 38. Calcium rich foods do not agree with you. & .73 \\
\hline 39. You do not like calcium rich foods. & .74 \\
\hline 40. Eating calcium rich foods means changing & .66 \\
\hline 41. In order to eat more calcium rich foods, & .57 \\
\hline 42. Calcium rich foods have too much & .64 \\
\hline \multicolumn{2}{|l|}{$\begin{array}{l}\text { Factor } 7 \text { Health Motivation } \\
\end{array}$} \\
\hline 43. You eat a well-balanced diet. & .50 \\
\hline 44. You look for new information related to & .79 \\
\hline 45. Keeping healthy is very important to you. & .73 \\
\hline 46. You try to discover health problems early. & .81 \\
\hline 47. You have a regular health check-up even & .50 \\
\hline 48. You follow recommendations to keep you & .74 \\
\hline \multicolumn{2}{|l|}{ Factor 8 Barriers to Vitamin D } \\
\hline 49. Vitamin D containing foods cost too much. & .76 \\
\hline 50. You do not like vitamin D containing & .76 \\
\hline 51. Eating vitamin D rich foods means & .70 \\
\hline 52. In order to eat more vitamin D rich foods, & .78 \\
\hline 53. Vitamin D rich foods have too much & .73 \\
\hline 54. An adequate vitamin D intake can be easily & .76 \\
\hline
\end{tabular}

*Factor loadings of $<0.35$ were omitted 
Modified Osteoporosis Self-Efficacy ScaleOSES-D. Content validity was established in the OSES-D similarly to the OHBS-D. Factor analysis was used to evaluate the validity of the original OSES structure as well as the additional vitamin D items. For factor analysis, the first three eigenvalues exceeded 1.0 and these results agreed with the scree plot. Therefore, three factors (Exercise, Calcium, and Vitamin D) for the OSES-D were extracted that explained $82.2 \%$ of the total variance. D. These factors extracted were identical to the original scale except the addition of the vitamin D subscale. All items related to a specific concept loaded under the specific subscale. Each item loaded meaningfully on only one factor; and each factor had multiple, significant item loadings. Factor loadings for the individual OSES-D items in each subscale are found in Table 2. Factor loadings ranged from .59-.89 demonstrating construct validity for the original OSES and the OSES-D.

Table 2.

Factor Loadings for the OSES-D Including Vitamin D Related Items

\begin{tabular}{|c|c|}
\hline Item & Loading \\
\hline \multicolumn{2}{|l|}{ Self-Efficacy- Exercise } \\
\hline 1. Begin a new or different exercise program & .62 \\
\hline 2. Change your exercise habits & 63 \\
\hline 3. Put forth the effort required to exercise & .89 \\
\hline 4. Do exercises even if they are difficult & .87 \\
\hline 5. Maintain a regular exercise program & .89 \\
\hline 6. Exercise for the appropriate length of time & .79 \\
\hline 7. Do exercises even if they are tiring & .88 \\
\hline 8. Stick to your exercise program & .88 \\
\hline 9. Exercise at least three times a week & .85 \\
\hline 10. Do the type of exercises that you are supposed to do & .84 \\
\hline \multicolumn{2}{|l|}{ Self-Efficacy - Calcium } \\
\hline 11. Begin to eat more calcium rich foods & .81 \\
\hline 12. Increase your calcium intake & .65 \\
\hline 13. Consume adequate amounts of calcium rich foods & .83 \\
\hline 14. Eat calcium rich foods on a regular basis & .89 \\
\hline 15. Change your diet to include more calcium rich foods & .81 \\
\hline 16. Eat calcium rich foods as often as you are supposed to & .84 \\
\hline 17. Select appropriate foods to increase your calcium intake & .74 \\
\hline 18. Stick to a diet which gives an adequate amount of calcium & .77 \\
\hline 19. Obtain foods that give an adequate amount of calcium & .77 \\
\hline 20. Remember to eat calcium rich foods & .70 \\
\hline 21. Take calcium supplements if you don't get enough calcium from your & .84 \\
\hline \multicolumn{2}{|l|}{ Self-Efficacy - Vitamin D } \\
\hline 22. Begin to eat more Vitamin D rich foods & .71 \\
\hline 23. Increase your Vitamin D intake & .76 \\
\hline 24. Consume adequate amounts of Vitamin D rich foods & .76 \\
\hline 25. Eat Vitamin D rich foods on a regular basis & .62 \\
\hline 26. Change your diet to include more Vitamin D rich foods & .69 \\
\hline 27. Eat Vitamin D rich foods as often as you are supposed to & .72 \\
\hline 28. Select appropriate foods to increase your Vitamin D intake & .77 \\
\hline 29. Stick to a diet which gives an adequate amount of Vitamin D & .70 \\
\hline 30. Obtain foods that give an adequate amount of Vitamin D & .80 \\
\hline 31. Remember to eat Vitamin D rich foods & .74 \\
\hline
\end{tabular}

*Factor loadings of $<0.35$ were omitted 


\section{Reliability}

Modified Osteoporosis Health Belief Scale-

OHBS-D. Table 3 indicates the Cronbach $\alpha$ coefficients, item-total correlations, and intraclass correlation coefficients for both the OHBS$\mathrm{D}$ and OSES-D subscales. All pre-set criteria were met for internal consistency and test-retest reliability of the OHBS-D. The overall Cronbach $\alpha$ was $r=.82$ and subscale Cronbach $\alpha$ 's ranged from $r=.75$-.87. Item-total correlations for each subscale ranged from .36-.78, including the modified vitamin D subscales items (benefits and barriers). Each of the subscales and subsequent items for such subscales contributed to increasing the overall scale internal consistency and therefore were retained. Therefore, the OHBS-D demonstrated internal consistency. The overall ICC for the OHBS-D was .79 and subscales ICCs ranged from .73-.87 indicating that the OHBS-D was test-retest reliable.

Table 3.

\begin{tabular}{|c|c|c|c|c|c|}
\hline Subscale & $\begin{array}{l}\text { Consistency an } \\
\text { Cronbach's } \alpha\end{array}$ & $\begin{array}{l}\text { etest Reliability for the } \\
\text { Cronbach's } \alpha \text { if item } \\
\text { deleted range }\end{array}$ & $\begin{array}{c}\text { HBS-D and OSES-D } \\
\text { Item-Total } \\
\text { Correlation Ranges }\end{array}$ & ICC & $\begin{array}{c}\text { ICC 95\% } \\
\text { CI }\end{array}$ \\
\hline \multicolumn{6}{|l|}{ OHBS-D } \\
\hline Total & $.82^{\mathrm{a}}$ & $.81-.82$ & - & $.79^{\mathrm{c}}$ & $.70-.86$ \\
\hline Susceptibility & $.87^{\mathrm{a}}$ & $.82-.87$ & $.54-.78^{\mathrm{b}}$ & $.82^{\mathrm{c}}$ & $.74-. .89$ \\
\hline Seriousness & $.75^{\mathrm{a}}$ & $.69-.75$ & $.36-.58^{\mathrm{b}}$ & $.76^{\mathrm{c}}$ & $.65-.84$ \\
\hline Benefits Exercise & $.86^{\mathrm{a}}$ & $.83-.86$ & $.55-.71^{\mathrm{b}}$ & $.83^{\mathrm{c}}$ & $.75-.89$ \\
\hline Benefits Calcium & $.81^{\mathrm{a}}$ & $.76-.79$ & $.49-.63^{b}$ & $.87^{\mathrm{c}}$ & $.81-.92$ \\
\hline Barriers to Exercise & $.84^{\mathrm{a}}$ & $.79-.84$ & $.51-.76^{\mathrm{b}}$ & $.82^{\mathrm{C}}$ & $.74-.88$ \\
\hline Barriers to Calcium & $.82^{\mathrm{a}}$ & $.76-.82$ & $.47-.72^{\mathrm{b}}$ & $.77^{\mathrm{c}}$ & $.67-.85$ \\
\hline Health Motivation & $.81^{\mathrm{a}}$ & $.75-.83$ & $.48-.67^{b}$ & $.85^{\mathrm{c}}$ & $.79-.91$ \\
\hline Benefits Vitamin D & $.85^{\mathrm{a}}$ & $.81-.83$ & $.58-.70^{\mathrm{b}}$ & $.83^{\mathrm{c}}$ & $.75-.88$ \\
\hline Barriers Vitamin D & $.84^{\mathrm{a}}$ & $.85-.87$ & $.67-.77^{\mathrm{b}}$ & $.73^{\mathrm{c}}$ & $.61-.83$ \\
\hline \multicolumn{6}{|l|}{ OSES-D } \\
\hline Total & $.98^{\mathrm{a}}$ & $.97-.98$ & $.44-.88^{b}$ & $.97^{\mathrm{c}}$ & $.95-.98$ \\
\hline Exercise & $.96^{\mathrm{a}}$ & $.96-.96$ & $.70-.89^{\mathrm{b}}$ & $.93^{\mathrm{c}}$ & $.90-.95$ \\
\hline Calcium & $.96^{\mathrm{a}}$ & $.95-.97$ & $.36-.91^{\mathrm{b}}$ & $.93^{\mathrm{c}}$ & $.89-.95$ \\
\hline Vitamin D & $.98^{\mathrm{a}}$ & $.97-.98$ & $.68-.96^{\mathrm{b}}$ & $.94^{\mathrm{c}}$ & $.92-.96$ \\
\hline
\end{tabular}

Note: CI indicates confidence interval; ICC, intra-class correlation coefficient; OHBS-D, Osteoporosis Health Belief Scale with

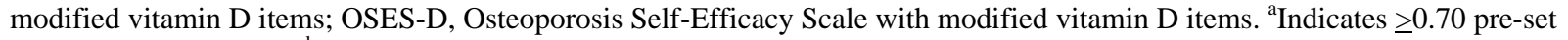

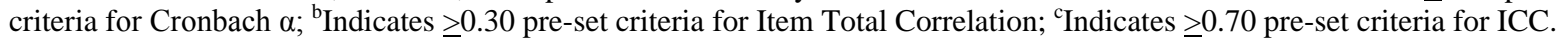

Modified Osteoporosis Self-Efficacy ScaleOSES-D. All pre-set criteria were met for internal consistency and test-retest reliability of the OSES-D. When assessing the internal consistency of the OSES-D, the overall Cronbach $\alpha$ for the OSES-D was $r=.98$ and subscales ranged from $r=.96-.98$. Therefore, the OSES-D demonstrated strong internal consistency. Item-total correlations for each subscale including the revised vitamin D subscale items ranged from .36-.96. Each of the subscales and subsequent items for such subscales contributed to increasing the overall scale internal consistency and therefore were retained. The overall ICC for the OSES-D was 
.97 and subscales ICCs ranged from .93-.94. Thus, this demonstrated the OSES-D was testretest reliable.

\section{Discussion}

The importance of this study and overall findings are that the modified scales (OHBS-D and OSES-D) which included vitamin D items were found to be valid and reliable in young adults. The validity and reliability in the modified scales were comparable to the original scales. The use of such scales is necessary as vitamin D intake is an important aspect of assessing osteoporosis health beliefs and selfefficacy for prevention and previous scales are lacking in the vitamin D related content.

\section{Validity}

In the OHBS-D, the addition of benefits of vitamin D subscale loaded on the same factor as benefits of calcium. These factor loadings are logical considering dietary calcium and dietary vitamin D are found in similar foods as well as being related in their mechanisms for bone health. However, barriers to vitamin D loaded on a separate factor. Barriers to obtaining adequate vitamin $\mathrm{D}$ may be different compared to barriers to obtaining calcium as vitamin $\mathrm{D}$ can be produced by UV light and therefore the latitude at which someone lives may determine vitamin D status (Holick et al., 2011). Additionally, it may be difficult to obtain adequate dietary vitamin $\mathrm{D}$ as natural foods sources of vitamin $\mathrm{D}$ are limited (Calvo, Whiting, \& Barton, 2004). These differences would support the separate factor loading of barriers to vitamin $\mathrm{D}$. The addition of the vitamin $\mathrm{D}$ related items also show factor loadings consistent with the original scale.

The factor analysis in the current study also indicated that the original scale exhibits construct validity as shown by the original authors (Kim et al., 1991). Additionally, the original OHBS was said to have construct validity from the original factor analysis that identified seven potential subscales (Kim et al., 1991). This also agrees with previous research using confirmatory factor analysis (Chan et al., 2007). The current study replicates the findings by the original authors as well as indicating that the modified vitamin $\mathrm{D}$ items added to the original scale demonstrate construct validity. The OHBS-D is thus considered a valid measure of osteoporosis related health beliefs that include vitamin D related items.

In the OSES-D, factor analysis results extracted a three-factor model related to self-efficacy and osteoporosis. All items loaded .55 or higher including the additional vitamin $\mathrm{D}$ items. The addition of the vitamin $\mathrm{D}$ subscale loading onto a separate factor suggests that vitamin D related items could be successfully added to the original OSES. Factor analysis also confirms the findings of Horan et al. (1998) which indicated the original scale demonstrated construct validity. This current study again replicates the findings by the original authors as well as indicating that modified vitamin $\mathrm{D}$ items demonstrate construct validity in the OSES-D. The OSES-D is therefore considered a valid measure of osteoporosis related self-efficacy that includes vitamin D related items.

\section{Reliability}

The OHBS has previously been studied and testretest reliability for the overall scale was found to be .90 , while the overall Cronbach $\alpha$ was .82 , indicating strong reliability (Kim et al., 1991). The findings from the current study confirm internal consistency and test-retest reliability for the OHBS (Chang, 2003; Piaseu, Belza, \& Mitchell, 2001; Johnson et al., 2008). The addition of vitamin D related items to the OHBS did not change the overall reliability. Moreover, the subscales of benefits to vitamin $\mathrm{D}$ and barriers to vitamin $\mathrm{D}$ were found to have strong internal consistency as well as contribute to strong test-retest reliability. Previous research has recognized that ICC values that range from $.60-.79$ show good test-retest reliability and an ICC of greater than .80 is thought to show strong test-retest reliability (March \& Sullivan, 1999). The OHBS-D subscales had ICC ranging .73-.87 and Cronbach $\alpha$ ranging from .75-.87, indicating strong reliability. Thus, the OHBS-D could be used as a reliable measure to assess osteoporosis-related health beliefs that include vitamin D related items. 
The original OSES has also been previously studied and found to have a strong internal consistency and test-rest reliability for each of the original subscales (exercise and calcium) (Horan et al., 1998). Findings from this current research agree with the original authors as well as others (Horan et al., 1998; Piaseu et al., 2001; Ali \& Twibell, 1995). The addition of vitamin D related items to the OSES did not change the overall reliability. Additionally, the subscale of vitamin D was found to have strong internal consistency (Cronbach $\alpha=.98$ ) and contribute to strong test-retest reliability (ICC=.97). Therefore, the OSES-D can be a reliable measure to evaluate self-efficacy and osteoporosis-related behaviors that include obtaining adequate vitamin D.

\section{Limitations and Implications}

Limitations of the current study include the small sample size $(\mathrm{n}=153)$ and use of a convenience sample. Our sample was homogenous with respect to population demographics that limit the generalization to white young adults, ages 18-23. Additionally, the sample comes from mostly middle-upper class families. This did not allow for psychometric analysis of different ethnicities, age groups, education groups,' or other confounding demographic characteristics. In the original development of the OHBS, sample size was 150, and in the development of the OSES, sample size was 201 (Kim et al., 1991; Horan et al., 1998). Our sample size of 153 was within this range and was larger than some previous scale development studies (Latimer, Walker, Kim, Pasch, \& Sterling, 2011; Ogedegbe, Mancuso, Allegrante, \& Charlson, 2003).

\section{Conclusion}

The purpose of this study was to determine the reliability and validity of modified osteoporosis health belief and osteoporosis self-efficacy scales. These study findings are important because valid and reliable scales that assess osteoporosis health beliefs and self-efficacy which include vitamin $\mathrm{D}$ related items are lacking. The OHBS-D and OSES-D are consistent measurement tools suitable for young adults. The revised items do not add much time to completing the scales and the findings support their validity, internal consistency, and testretest reliability. Further testing of the OHBS-D and OSES-D with larger sample sizes over longer periods of time with diverse populations may be needed to support these findings. The current study's findings support the use of both scales in educational programs as instruments to assess and consistently evaluate health beliefs and self-efficacy related to osteoporosis in young adults.

\section{References}

Ali, N. S., \& Twibell, R. K. (1995). Health promotional and osteoporosis prevention among postmenopausal women. Preventative Medicine, 24(5), 628-534. doi: 10.1006/pmed.1995.1083

Bandura, A. (1977). Self-efficacy: Toward a unifying theory of behavioral change. Psychological Review, 84(2), 191-215. doi: 10.1037/0033-295X.84.2.191

Calvo, M. S., Whiting, S. J., \& Barton, C. N. (2004). Vitamin D fortification in the United States and Canada: Current status and data needs. American Journal of Clinical Nutrition, 80(6), 1710S1716S.

Chan, M. F., Kwong, W. S., Zang, Y., \& Wan, P. Y. (2007). Evaluation of an osteoporosis prevention education programme for young adults. Journal of Advanced Nursing, 57(3), 270-285. doi: 10.1111/j.1365-2648.2006.04091.x

Chang, S.-F. (2006). A cross-sectional survey of calcium intake in relation to knowledge of osteoporosis and beliefs in young adult women. International Journal of Nursing Practice, 12(1), 21-27. doi: 10.1111/j.1440-172X.2006.00546.X

Chang, S.-F., Chen, C.-M., Chen, P.-L., \& Chung, U.-L. (2003). Predictors of community's women osteoporosis prevention Intention-A pilot study. Journal of Nursing Research, 11(4), 231-239. doi: 10.1097/01.JNR.0000347642.33465.8e 
Cline, R. R. \& Worley, M. M. (2006). Osteoporosis health beliefs and self-care behaviors: An exploratory investigation. Journal of the American Pharmacists Association, 46, 356-363. doi:10.1331/154434506777069534

Costello, A. B., \& Osborne, J. W. (2005). Best practices in exploratory factor analysis: Four recommendations for getting the most from your analysis. Practical Assessment, Research and Evaluation, 10(7), 1-9.

Dell, R. M., Greene, D., Anderson, D., \& Williams, K. (2009). Osteoporosis disease management: What every orthopaedic surgeon should know. Journal of Bone \& Joint Surgery, 91, 79-86. doi:org/10.2106/JBJS.I.00521

Gammage, K. L., Francoeur, C., Mack, D. E., \& Klentrou, P. (2009). Osteoporosis health beliefs and knowledge in college students: The role of dietary restraint. Eating Behaviors, 10(1), 65-67. doi: 10.1016/j.eatbeh.2008.10.006

Heaney, R. P., Abrams, S., Dawson-Hughes, B., Looker, A., Marcus, R., Matkovic, V., \& Weaver, C. (2000). Peak bone mass. Osteoporosis International, 11(12), 985-1009. doi:10.1007/s001980070020

Holick, M. F., Binkley, N. C., Bischoff-Ferrari, H. A., Gordon, C. M., Hanley, D. A., Heaney, R., et al. (2011). Evaluation, treatment, and prevention of vitamin D deficiency: an endocrine society clinical practice guideline. Journal of Clinical Endocrinology and Metabolism, 96(7), 1911-1930. doi: http://dx.doi.org/10.1210/jc.2011-0385

Horan, M. L., Kim, K. K., Gendler, P., Froman, R. D., \& Patel, M. D. (1998). Development and evaluation of the Osteoporosis Self-Efficacy Scale. Research in Nursing and Health, 21, 395-403. doi: 10.1002/(SICI)1098-240X(199810)

Johnson, C. S., McLeod, W., Kennedy, L., \& McLeod, K. (2008). Osteoporosis health beliefs among younger and older men and women. Health Education \& Behavior, 35, 721-733. doi: $10.1177 / 1090198107301331$

Kim, K., Horan, M., Gendler, P., \& Patel, M. (1991). Development and evaluation of the osteoporosis health belief scale. Research in Nursing, 14, 155-163. doi: 10.1002/nur.4770140210

Latimer, L., Walker, L. O., Kim, S., Pasch, K. E., \& Sterling, B. S. (2011). Self-efficacy scale for weight loss among multi-ethnic women of lower income: A psychometric evaluation. Journal of Nutrition Education and Behavior, 43(4), 279-283. doi: 10.1016/j.jneb.2010.09.007

Lloyd, T., Petit, M. A., Lin, H-M., \& Beck, T. J. (2004). Lifestyle factors and the development of bone mass and bone strength in young women. The Journal of Pediatrics, 144(6), 776-782. doi: 10.1016/j.jpeds.2004.02.047

Mack, D., Gammage, K., \& Klentrou, P. (2006). The Osteoporosis Health Belief Scale: Factorial validity in a university sample. Journal of Sport and Exercise Psychology, 28, S125.

March, J. S., \& Sullivan, K. (1999). Test-retest reliability of the Multidimensional Anxiety Scale for Children. Journal of Anxiety Disorders, 13, 349-358. doi: 10.1016/S0887-6185(99)00009-2

National Osteoporosis Foundation (2008). Clinician's guide to prevention and treatment of osteoporosis. Retrieved 23 May, 2010, from http://www.nof.org/professionals/Clinicians_Guide.htm.

Nunnally, J. C. \& Bernstein, I. H. (1994). Psychometric Theory. $3^{\text {rd }}$ ed. New York, NY: McGraw-Hill.

Ogedegbe, G., Mancuso, C. A., Allegrante, J. P., \& Charlson, M. E. (2003). Development and evaluation of a medication adherence self-efficacy scale in hypertensive African-American patients. Journal of Clinical Epidemiology, 56(6), 520-529. doi: 10.1016/S0895-4356(03)00053-2

Piaseu, N., Belza, B., \& Mitchell, P. (2001). Testing the effectiveness of an osteoporosis educational program for nursing students in Thailand. Arthritis Care and Research, 45(3), 246-251. 10.1002/1529-0131(200106)45:3<246::AID-ART256>3.0.CO;2-Y.

Robitaille, J., Yoon, P. W., Moore, C. A., Liu, T., Irizarr-Delacrus, M., Looker, A. C., \& Khoury, M. J. (2008). Prevalence, Family History, and Prevention of Reported Osteoporosis in U.S. Women. American Journal of Preventive Medicine, 35, 47-54. doi: 10.1016/j.amepre.2008.03.027

Rosenstock, I. M., Strecher, V. J., \& Becker, M. H. (1988). Social Learning Theory and the Health Belief Model. Health Education \& Behavior, 15(2), 175-183. doi: 10.1177/109019818801500203 
Sedlak, C. A., Doheny, M. O., \& Estok, P. J. (2000). Osteoporosis in older men: Knowledge and health beliefs. Orthopaedic Nursing, 19(3), 38-42.

Sedlak, C. A., Doheny, M. O., Estok, P. J., Zeller, R. A., \& Winchell, J. (2007). DXA, health beliefs and osteoporosis prevention behaviors. Journal of Aging and Health, 19, 742-756. doi: $10.1177 / 0898264307304303$

Tussing, L., \& Chapman-Novakofski, K. (2005). Osteoporosis prevention education: Behavior theories and calcium intake. Journal of the American Dietetic Association, 105(1), 92-97. doi: 10.1016/j.jada.2004.10.025

Wallace, L. S. (2002). Osteoporosis prevention in college women: Application for the expanded health belief model. American Journal of Health Behavior, 26(3), 163-172. doi: http://dx.doi.org/10.5993/AJHB.26.3.1

Wier, J. P. (2005). Quantifying test-retest reliability using the intraclass correlation coefficient and the SEM. Journal of Strength and Conditioning Research, 19(1), 231-240. doi:10.1519/15184.1

Ziccardi, S. L., Sedlak, C. A., \& Doheny, M. O. (2004). Knowledge and health beliefs of osteoporosis in college nursing students. Orthopaedic Nursing, 23, 128-133. doi:10.1097/00006416-20040300000010

\author{
$\underline{\text { Author Information }}$ \\ *Alexa Evenson \\ Assistant Professor \\ Nutrition Department \\ The College of Saint Benedict/Saint John's University \\ 37 South College Avenue \\ St. Joseph, MN, 56374 \\ Phone: (320)363-5295 \\ Fax: (320)-363-5582 \\ E-mail: aevenson@csbsju.edu \\ Gregory Sanders \\ Professor and Associate Dean \\ College of Human Development and Education, \\ North Dakota State University PO Box 6050, \\ Fargo, ND 58108-6050 \\ Phone: (701) 231-8272 \\ E-mail: Greg.Sanders@ndsu.edu \\ * corresponding author
}

